\title{
Population dynamics of the red-eared slider (Trachemys scripta elegans) with changes in the population dependent carrying capacity in Republic of Korea
}

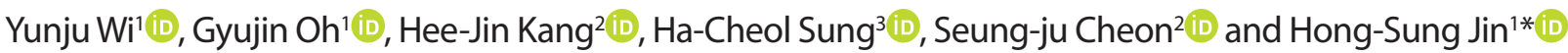 \\ 'Department of Mathematics \& Statistics, Chonnam National University, Gwangju 61186, Republic of Korea \\ ${ }^{2} S$ chool of Biological of Sciences and Biotechnology, Chonnam National University, Gwangju 61186, Republic of Korea \\ ${ }^{3}$ Department of Biological Sciences, College of Natural Sciences, Chonnam National University, Gwangju 61186, Republic of Korea
}

\section{ARTICLE INFO}

Received September 28, 2021

Revised November 24, 2021

Accepted November 30, 2021

Published on January 7, 2022

${ }^{*}$ Corresponding author Hong-Sung Jin

E-mail hjin@jnu.ac.kr
Background: In this study, we proposed that the population dynamics of non-native red-eared sliders (Trachemys scripta elegans) depends on the species' habitat extension and survivorship. We used a logistic equation with time-dependent habitat carrying capacity. In detail, the present carrying capacity depends on the red-eared slider population of the previous year. Anthropogenic activities such as the abandonment of previously captive red-eared sliders or the release due to religion customs would supply new habitats to the species. Therefore we assumed that anthropogenic spread increases the habitat carrying capacity. Based on the urbanization increase rate of 3\% in Korea from 1980 to 2000 , we assumed an annual spread of $3 \%$ to simulate the population dynamics of the red-eared slider. In addition, the effect on the population of an increase of natural habitats due to migration was simulated.

Results: The close relationship between the distributions of non-native red-eared sliders and of urbanized areas demonstrates that urbanization plays an important role in providing new habitats for released individuals. Depending on the survivorship, the population of the red-eared slider in Korea increased 1.826 to 3.577 times between 1980 and 2000. To control population growth, it is necessary to reduce carrying capacity by reducing habitat expansion through prohibition of release into the wild ecosystem and careful managements of the wetland or artificial ponds. Changes in the habitat carrying capacity showed that the population fluctuated every other year. However, after several years, it converged to a consistent value which depended on the survivorship. Further, our results showed that if red-eared sliders expand their habitat by natural migration, their population can increase to a greater number than when they have a $99 \%$ survivorship in a fixed habitat.

Conclusions: Further introductions of red-eared sliders into wetlands or artificial ponds should be prohibited and managed to prevent future spread of the species. Moreover, it is important to reduce the species' survivorship by restoring disturbed ecosystems and maintaining healthy ecosystems.

Keywords: carrying capacity, habitat, population dynamics, red-eared slider, survivorship

\section{Introduction}

From the late 1970s, large quantities of the red-eared slider (Trachemys scripta elegans) were imported into the Republic of Korea until the country's Ministry of Environment (MOE) banned the species by declaring it an ecological disturbance in 2001 (MOE 2016). As red-eared sliders grow, taking care of them as pets becomes more difficult. Consequently, large quantities of individuals were released into areas with easy accessibility for humans (Jung 2014; Jung and Lee 2019; Koo et al. 2017; Reed and Gibbons
2003; Warwick et al. 1990). In addition, each year, many red-eared sliders were introduced into the wild during religious ceremonies in Korea (MOE 2009). Red-eared sliders are able to adapt to various ecological conditions, and can cause severe ecosystem disturbance and damage (Gibbons 1990; Jung and Lee 2019). Several studies on this non-native species have been carried out, focusing on the distribution status (Koo et al. 2017; Koo et al. 2020; Oh et al. 2017), population monitoring (Lee et al. 2015), migration patterns, and habitat use (Jo et al. 2017). Unlike other exotic turtles, red-eared sliders have been found with high frequency in a 
wide range of habitats types (Koo et al. 2017; Koo et al. 2020; Oh et al. 2017). In Korea, juvenile individuals have been detected in the wild, which suggests that the species reproduces and spreads naturally (Koo et al. 2017). Further, natural migration of the red-eared slider has been reported by Koo et al. (2019). Moreover, a survey on Jeju Island in 2015 confirmed that the red-eared slider can hybridize with the river cooter (Pseudemys concinna) and the yellow-bellied slider (Trachemys scripta scripta) (Lee et al. 2015). Successful invasion consists of three essential stages: the introduction of organisms to a new environment, the establishment and increase of the local population, and successful spread throughout the landscape (Shea and Chesson 2002). The red-eared slider has already adapted to its new environment outside captivity and can reproduce naturally (Lee et al. 2015).

In this study, we simulated the annual dynamics of nonnative red-eared slider populations in relation to the habitat expansion and survivorship in new habitats. The spread of the species can be divided into anthropogenic and natural spread. Anthropogenic spread defines the introduction and settlement of the species into new habitats through release by humans. This type of spread is closely related to urbanization (Koo et al. 2017). In Korea, urbanization has progressed rapidly since the 1970s. Therefore, we assume that the spread of red-eared sliders has continued with the ongoing urbanization. If the species adapts to a new environment and reproduces, natural spread to new areas will occur due to migration (Koo et al. 2017), which has been confirmed for the eared slider in Korea (Koo et al. 2019). If the available habitat increases due to the combination of both anthropogenic and natural factors, the red-eared slider population will also increase.

We developed a logistic model and simulated several spread scenarios for the red-eared slider to identify the factors affecting its population dynamics. Our study provides important information for appropriate population control and removal through the predictions of future proliferation.

\section{Materials and Methods}

\section{Population dynamics of the red-eared slider}

We used a logistic equation with time-dependent habitat carrying capacity, expressed as:

$$
\frac{\mathrm{d} N(t)}{\mathrm{dt}}=\gamma N(t)-C \frac{N^{2}(t)}{K(t)}
$$

where $N(t)$ represents the red-eared slider population size, $K(t)$ is the carrying capacity, and $\gamma$ represents the intrinsic growth rate. The constant $C$ represents a logistical regulating term (Jin et al. 2017; Yukalov et al. 2012).

The carrying capacity is a function of the population at the time of $t-\tau$, such that:

$$
K(t)=A(t)-B(\cdot) N(t-\tau) .
$$

In equation (2), $A(t)$ represents the habitat size, which can be altered by the spread to new habitats, whereas $B(\cdot)$ represents the red-eared slider survivorship.

With normalizing $N(t)$ by $N_{\text {unit }}$, which is the counting unit used for the red-eared slider (i.e., hundreds or thousands), the relative and dimensionless red-eared slider population size $x(t)$ was defined as

$$
x(t)=\frac{N(\mathrm{t})}{N_{\text {unit }}} .
$$

Substituting $\alpha=\frac{\gamma}{C} \frac{A}{N_{\text {unit }}}$ and $\beta=\frac{\gamma}{C} B$ converts the logistic equation (1) to

$$
x^{\prime}(t)=x(t)-\frac{x^{2}(t)}{y(x)}
$$

The effective carrying capacity $y(x)$, which is the normalized and dimensionless version of the carrying capacity, was defined as

$$
y(x)=\alpha(t)-\beta(\cdot) x(t-\tau) .
$$

The variable $\alpha$ represents the dimensionless habitat size, whereas $\beta(\cdot)$ represents the scaled red-eared slider survivorship, which can be affected by environmental factors such as predation, dissolved oxygen levels, temperature distribution, food availability. A summary of these key parameters is presented in Table 1.

To simulate annual population dynamics, we set the delay time $\tau$ as one year. Then the population between the year of $[n, n+1]$ can be expressed as

$$
x(t)=\frac{x_{n}\left(y\left(x_{n}\right)\right) e^{t}}{y\left(x_{n}\right)+x_{n}\left(e^{t}-1\right)} .
$$

where $x_{n}$ represents the initial population of red-eared slider at the beginning of the $\mathrm{n}^{\text {th }}$ year. The effective habitat carrying capacity between the year of $[n, n+1]$ is

$$
y\left(x_{n}\right)=\alpha_{n}-\beta(\cdot) x_{n}
$$

\section{Algorithm}

As more than one million red-eared sliders were imported and sold in Korea from the late 1970s to 2001 (MOE 2009), we simulated the species' population dynamics for twenty years. The distribution of the red-eared slider is associated with urbanized areas (Koo et al. 2017) and was assumed to increase by approximately 3\% per year, comparable to the rate of urbanization of 3\% in Korea from 1980 to 2000 (Fig. 1) (Macrotrends 2021). Thereafter, population changes in habitats were estimated over twenty years, assuming that anthropogenic habitats would no longer spread. In 2001-2020, the red-eared sliders had been re- 
Table 1 Summary of parameters used

\begin{tabular}{|c|c|c|}
\hline Parameter & Definition & Comments \\
\hline$\alpha$ & Habitat carrying capacity & $\begin{array}{l}\text { Dimensionless unit } \\
\text { The natural habitat carrying capacity } \alpha \text { was set to two units }\end{array}$ \\
\hline$\beta$ & $\begin{array}{l}\text { Red-eared slider survivorship, } \\
\text { affected by habitat } \\
\text { condition }\end{array}$ & $\begin{array}{l}-1<\beta<1 \\
\text { Positive values closer to zero represent better conditions for red-eared slider } \\
\text { survivorship. Negative values indicate habitat increase by natural spread of sliders }\end{array}$ \\
\hline$x_{n}$ & $\begin{array}{l}\text { Population at the beginning } \\
\text { of the } \mathrm{n}^{\text {th }} \text { year }\end{array}$ & $\begin{array}{l}\text { Dimensionless unit } \\
\text { Initial population for time interval }[n, n+1]\end{array}$ \\
\hline$y_{n}=\alpha-\beta x_{n}$ & $\begin{array}{l}\text { Effective habitat carrying } \\
\text { capacity }\end{array}$ & $\begin{array}{l}\text { Dimensionless unit } \\
\text { Constant habitat carrying capacity for time interval }[n, n+1]\end{array}$ \\
\hline
\end{tabular}

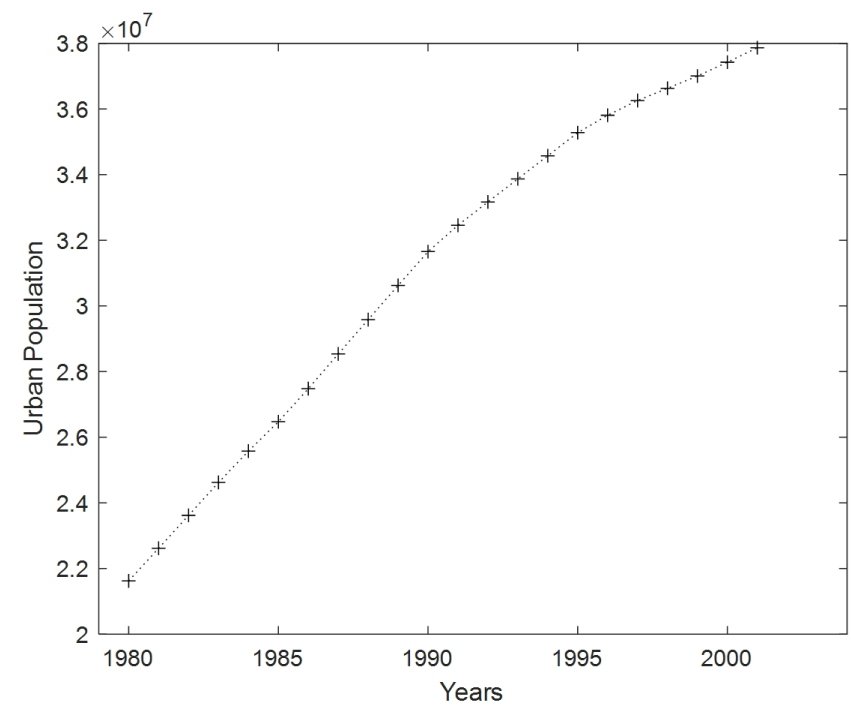

Fig. 1 Urban population in South Korea from 1980 to 2000. The population increased on average by $2.79 \%$, which can be referred to as the anthropogenic habitat expanding rate. The habitat increase rate of red-eared sliders was set to $3 \%$ in the simulations.

leased, possibly increasing their habitat. However, a distinction was made between before and after the law bans the import of red-eared sliders. Moreover, urbanization after 2001 has been very slow. Since 2001, the urbanization growth rate has been less than $1 \%$ and has recently been stagnant, so the period from 2001 to 2020 was simulated as the settlement period.

Red-eared sliders have a general survivorship of $1 \%$ in their native range (Feldman 2007), but may have much higher survivorship in invaded areas. Thus, population dynamics were estimated under different survivorship scenarios. The survivorship in the new habitats was set to $1 \%$, $50 \%$, or $99 \%$, depending on the ecosystem conditions.

The following algorithms were applied to calculate the annual population size as the habitat increases.

\section{Increasing habitat model}

1) Initial red-eared slider population size $x_{0}$ was set to one unit, which could be a thousand or a million.

2) The initial habitat carrying capacity $\alpha$ was set to two units (Initial habitat size, defined as the area available for habitat in units of population, was set as approximately twice the initial settlement population).

3) New habitat was produced every year, at a rate of a $3 \%$ increase in $\alpha$.

4) Survivorships at the habitat were set to $\beta=0.99, \beta=0.50$, $\beta=0.01$, and $\beta=-0.05$.

5) The annual habitat carrying capacity was calculated.

6) The population size was evaluated to get $x_{1}$, which is the initial population size for the next year.

7) Repeat steps 3 to 6 for twenty years.

\section{Non-increasing habitat model}

1) Initial population size $x_{0}$ was set to 3.577 units after the first 20 years had passed in the simulation with $\beta=$ 0.01 .

2) No further habitat increase was assumed.

3) The population size for the next 20 years were obtained for $\beta=0.99, \beta=0.50$, and $\beta=0.01$ under conditions in which the habitat size was maintained at $\alpha=3.612$ units.

\section{Resullts}

\section{Increasing habitat model}

The red-eared slider population size and the effective habitat carrying capacity were calculated using equation (6). The population growth patterns for the three red-eared slider survivorship scenarios over a period of twenty years under the assumption that the amount of artificial habitat increased by 3\% per year are shown in Figure 2. Although the bottom curve reflects poor survival conditions (i.e., $\beta=$ 0.99 , it revealed an increase of the population to 1.826 units. The middle curve portrayed similar trends under a survivorship of $\beta=0.01$, with red-eared slider populations converging to 3.576 units. A $\beta$ value of 0.99 implies that only $1 \%$ of red-eared sliders survived to the next year, suggesting high predator pressure and poor survival conditions. In contrast, $\beta=0.01$ represented a scarcity of predators and favorable conditions for red-eared slider survivorship, with $99 \%$ of the population surviving to the following year. A $\beta$ value of -0.05 meant that $5 \%$ of the red-eared sliders moved 


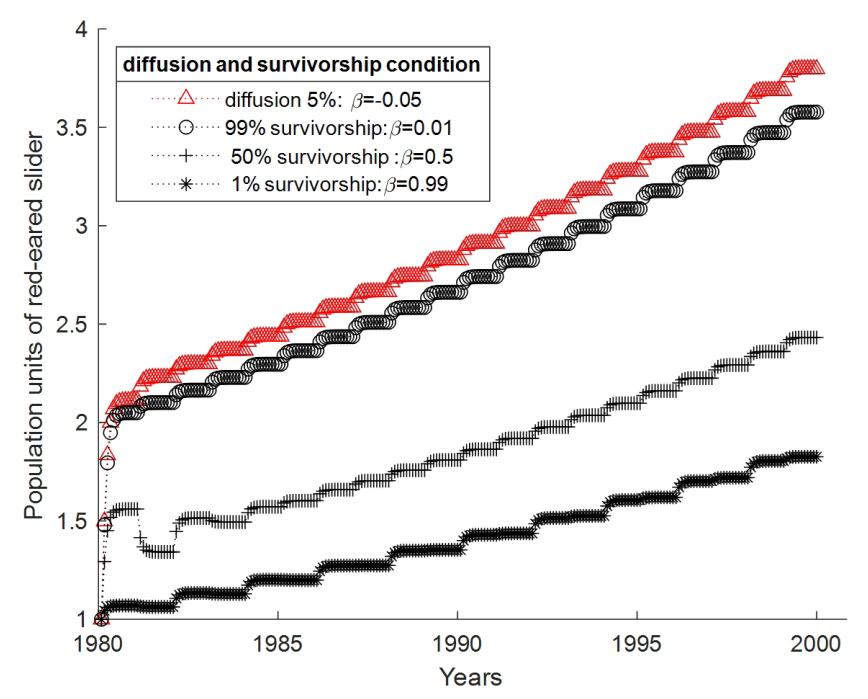

Fig. 2 Population growth of red-eared slider for 1980-2000, assuming an annual habitat increase of $3 \%$. The survivorship for red-eared slider is represented by $\beta$. Higher values of $\beta$ indicate poorer conditions for survival. The top " $\triangle$ " line represents a habitat increase of $5 \%$ per year for $\beta=-0.05$ representing natural

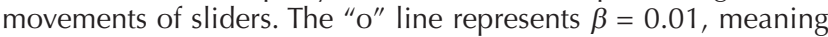
that $99 \%$ of red-eared sliders survive. The " + " line represents poor conditions for $50 \%$ survivorship and the "*" line represents poor conditions for $1 \%$ survivorship.

Table 2 The variation of the red-eared slider population for 1980 2000

\begin{tabular}{ccc}
\hline$\beta$ & $\begin{array}{c}\alpha: \text { habitat units } \\
\text { after 20 years }\end{array}$ & $\begin{array}{c}x_{20}: \text { population units } \\
\text { after 20 years }\end{array}$ \\
\hline 0.99 & 3.612 & 1.826 \\
0.50 & 3.612 & 2.432 \\
0.01 & 3.612 & 3.577 \\
-0.05 & 3.612 & 3.797 \\
\hline
\end{tabular}

It shows the change in the population of the red-eared slider population $x(t)$, assuming that the habitat is increasing at an annual rate of $3 \%$ for 1980-2000, from an initial value of $\alpha=2$. The red-eared slider survivorship is fixed at and $\beta=0.99, \beta=0.50, \beta=0.01$, and $\beta=-0.05$. The value of $\beta=0.99$ indicate conditions with red-eared slider survival of $1 \%$, while $\beta=-0.05$ represents a natural spread of $5 \%$

to new habitat due to natural spread. The simulation showed that if red-eared sliders migrate naturally to expand their habitat, their population can increase to a greater number of individuals than when they have a $99 \%$ survivorship in a fixed habitat.

The results for the red-eared slider population $x(t)$ under the assumptions of the increasing habitat model are summarized in Table 2.

\section{Non-increasing habitat model}

After the first twenty years with increasing habitat availability, no further increase of anthropogenic habitat was assumed for the next twenty years. The red-eared slider populations for the three levels of survivorships under these assumptions are compared in Table 3. The population size for 2000 was set at 3.577 units. Under poor survivorship (i.e., $\beta=0.99$ ), the population sizes converged to 1.826 units
Table 3 Convergent population units for various cases of survivorship

\begin{tabular}{ccc}
\hline $\begin{array}{c}\alpha \text { habitat } \\
\text { unit }\end{array}$ & \multicolumn{1}{c}{$\beta$ : red-eared slider } \\
survivorship & $\begin{array}{c}\text { Convergent } \\
\text { population units }\end{array}$ \\
\hline 3.612 & $\beta=0.01: 99 \%$ survivorship & 3.576 \\
3.612 & $\beta=0.05: 50 \%$ survivorship & 2.432 \\
3.612 & $\beta=0.09: 1 \%$ survivorship & 1.826
\end{tabular}

It shows the convergent population units for various cases of red-eared slider survivorship with $\alpha=3.612$ calculated by $3 \%$ increase per year for 1980-2000, which is the initial habitat unit in 2000 after 20 years of anthropogenic spread from $\alpha=2$. The initial population size is set to 3.577 units. For extremely good survivorship condition of $\beta=0.01$ the population size is almost unchanged, while for poor condition of $\beta=$ 0.99 the population size converges to 1.826 unit close to half of the initial population size

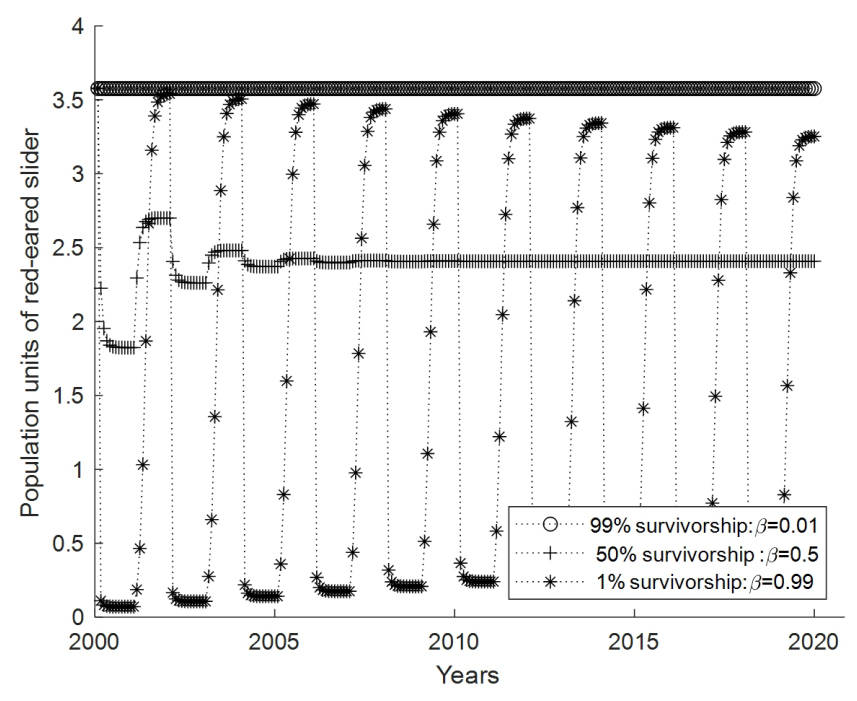

Fig. 3 Population units of the red-eared slider for 2000-2020. The population size at the beginning year of 2000 was set to 3.577 units. The "*" line represents the population variation for $\beta=$ 0.99 , meaning that $1 \%$ of red-eared sliders survive. The size of the population increases and decreases rapidly every other year according to the new effective capacity. The population size exhibit large-amplitude fluctuations over alternating years. This means you can find a lot of red-eared sliders in one year and hard to find sliders in the following years. The " + " line shows that population size exhibits medium amplitude fluctuations for $\beta=0.5$. The "o" line for $\beta=0.01$. The "*" line exhibits the population variation for $\beta=0.01$, under favorable conditions for red-eared sliders, maintaining a high population size of 3.576 units.

and exhibited large-amplitude fluctuations over alternating years ("+" line in Fig. 3). The size of the population increases and decreases rapidly every other year according to the new effective capacity. These oscillations show a biennial pattern of population changes, despite only $1 \%$ of survivors. This means you can find a lot of red-eared sliders in one year and hard to find sliders in the following years. For the intermediate case $(\beta=0.5)$, population sizes showed medium amplitude fluctuations ("o" line in Fig. 3). Under favorable conditions $(\beta=0.01)$, populations exhibited minimal variation and maintained high population size of 3.576 units (“*” line in Fig. 3). Changes in carrying capacity showed that the red-eared slider population fluctuated every other year. However, after several years, it converged to 
a certain value depending on the survivorship.

\section{Discussion}

During the period of rapid urbanization from 1980 to 2000 , active imports of red-eared sliders occurred in Korea, and many individuals were released into the wild near urban areas. Considering that the distribution of the species is closely related to urbanized areas (Koo et al. 2017), it can be assumed that urbanization played an important role in providing habitats for the release of previously captive redeared sliders. We chose an average urbanization rate of alpha $=0.03$ from 1980 to 2000 as the habitat growth rate for red eared slider, because the red-eared slider was released near urban areas. In 2001-2020, the red-eared sliders had been released, possibly increasing their habitat. However, a distinction was made between before and after the law bans the import of red-eared sliders. Moreover, urbanization after 2001 has been very slow. Since 2001, the urbanization growth rate has been less than $1 \%$ and has recently been stagnant, so the period from 2001 to 2020 was simulated as the settlement period.

According to simulation results, it is necessary to reduce the amount of habitat available to the red-eared slider to reduce its non-native population. However, because it is difficult to artificially remove the habitat, preventing the species' further spread should be the top priority. To prevent further anthropogenic spread of red-eared sliders, local governments should issue legislations which prohibit the species' release and movement after capture. In addition, appropriate management and control approaches need to be developed for the habitats invaded by red-eared sliders (i.e., artificial wetlands and ecological parks). Further, early detection of the invasive species is another factor that should be implemented in management strategies. Effective detection methods may increase the chances of finding the species at a smaller population size, lessening the extent of damages to the ecosystem (Huxel 1999; Lowe et al. 2000; Mehta et al. 2007). Moreover, to manage an invasive species efficiently, it is necessary to understand the ecological requirements of the species (Gibbons 1986; Jung and Lee 2019). Since species' characteristics in the new habitats may differ between regions (Taniguchi et al. 2017), information obtained from studies on physiological characteristics, such as diet and growth rate, can help to prepare efficient management plans (Donlan and Martin 2004). Finally, ecological characteristics should be considered to lower the survivorship of red-eared sliders. For this, natural removal of spawning grounds i.e., by maintaining populations of turtle egg predators like ants, raccoons, moles, and ground mice (Perez-Santigosa et al. 2008) and artificial removal of spawning grounds (Cadi et al. 2004) may be possible strategies. It is also important to reduce the survivorship of red- eared sliders by restoring or maintaining a healthy condition of the ecosystem.

If field data by year are available, even spatial changes in the population can be included. The basic equation can be extended by modifying the carrying capacity to add spatial parameters such as latitude and longitude. In this case, various ecological information related to red eared sliders, such as habitat conditions, food, predators, and competitors, is required

\section{Movement of red-eared sliders}

Based on high discovery frequencies and reports of natural reproduction (MOE 2006), it can be assumed that redeared sliders adapted to their new environment and that there is ample potential for further spread of the species. An increased population density caused by introduction decreases the individual food intake rate (Alonso et al. 1994). Furthermore, it results in the natural spread of the species.

Long-distance movement of turtles is caused by factors such as nest site selection, seasonal migration, departure from unfavorable habitat conditions, and movement by males in search of females (Gibbons 1986). Generally, they do not travel long distances unless forced due to natural disasters (e.g., floods). It is estimated that red-eared sliders move approximately $600 \mathrm{~m}$ to $800 \mathrm{~m}$ away from the water system (Koo et al. 2019). The average moving distances of two red-eared sliders, confirmed through radio tracking in a river environment, was $425.00 \mathrm{~m} \pm 94.84 \mathrm{~m}$ and $543.00 \mathrm{~m} \pm$ $11.27 \mathrm{~m}$, respectively (Koo et al. 2012). The distance confirmed through the capture-recapture method was as far as $5 \mathrm{~km}$ for males and up to $3 \mathrm{~km}$ for females (Morreale et al. 1984). In addition, compared to females, males are more active in early spring and late autumn. It is assumed that during this time the females are nesting.

Natural spread of red-eared sliders has been reported in Korea (Koo et al. 2019). Therefore, we included the natural spread in our simulations to estimate the red-eared slider population. Taking natural migration into account, the simulations showed that even if $1 \%$ of the population migrates, habitat growth is much greater than the number estimated based on the maximum survivorship.

\section{Conclusions}

To control the invasion of red-eared sliders in Korea, the anthropogenic spread of the species needs to be restricted and natural ecosystems have to be recovered. The recovery of natural ecosystems would also contribute to lowering the convergence point of the red-eared slider population. More importantly, to curb population growth, the habitat carrying capacity needs to be decreased by reducing further spread. For this, regulations to prohibit the release the spe- 
cies into the wild, and appropriate management plans for the wetlands or artificial ponds must be implemented. This requires the continuous ecological monitoring of the habitat status as well as risk assessments. To restore or maintain the ecosystem balance, anthropogenic spread must be strictly controlled by law and by volunteers.

\section{Abbreviations}

MOE: Ministry of Environment.

\section{Acknowledgements}

We would like to thank the reviewers for their thoughtful comments and efforts towards improving our manuscript.

\section{Authors' contributions}

YJW carried out the field study, performed the analysis, and wrote the manuscript. GJO, HCS, HJK, and SJC participated in the design of the study and reviewed the manuscript. HSJ developed the study concept and reviewed the manuscript. All authors read and approved the final manuscript.

\section{Funding}

This study was supported by the Korea Environment Industry \& Technology Institute (KEITI) through the Project for the Development of Biological Diversity Threats Outbreak Management Technology (2018002270004), funded by Korean Ministry of Environment (MOE). Additional funding was provided by the National Research Foundation of Korea (NRF), which is funded by the Ministry of Education, Republic of Korea (NRF-2020R1I1A3071769).

\section{Availability of data and materials}

The datasets generated and/or analyzed during this study are available from the corresponding author upon reasonable request.

\section{Ethics approval and consent to participate}

Not applicable.

\section{Consent for publication}

Not applicable.

\section{Competing interests}

The authors declare that they have no competing interests.

\section{References}

Alonso JC, Alonso JA, Bautista LM. Carrying capacity of staging areas and facultative migration extension in common cranes. J Appl Ecol. 1994;31(2):212-22. https://doi.org/10.2307/2404537.

Cadi A, Delmas V, Prévot-Julliard AC, Joly P, Pieau C, Girondot M. Successful reproduction of the introduced slider turtle (Trachemys scripta elegans) in the South of France. Aquatic Conserv: Mar Freshw Ecosyst. 2004;14(3):237-46. https://doi.org/10.1002/aqc.607.

Donlan CJ, Martin PS. Role of ecological history in invasive species management and conservation. Conserv Biol. 2004;18(1):267-9. http://www.jstor.org/stable/3589138.

Feldman ML. The red-eared slider turtle (Trachemys scripta elegans) in New Zealand. Turtle Tortoise Newsl. 2007;10:15-8. https://doi. org/10.2744/1526-3096(2007)10[2:TNOCCA]2.0.CO;2.

Gibbons JW. Life history and ecology of the slider turtle. Washington, DC: Smithsonian Institution Press; 1990.

Gibbons JW. Movement patterns among turtle populations: applicability to management of the desert tortoise. Herpetologica. 1986;42(1):10413.

Huxel GR. Rapid displacement of native species by invasive species: effects of hybridization. Biol Conserv. 1999;89(2):143-5. https://doi. org/10.1016/S0006-3207(98)00153-0.

Jin HS, Han D, Kim JH, Shin HJ, Yoon YH, Han CH. Simulations of the population dynamics of jellyfish polyps living on artificial substrates in coastal areas. Thalassas. 2017;33(1):43-50. https://doi.org/10. 1007/s41208-016-0019-5.

Jo SI, Na S, An CK, Kim HJ, Jeong YJ, Lim YM, et al. Comparison analysis for using the habitat pattern between the Korean endangered species, Mauremys reevesii, and the exotic species, Trachemys scripta elegans. Korean J Environ Ecol. 2017;31(4):397-408. https://doi. org/10.13047/KJEE.2017.31.4.397.

Jung JH, Lee WS. Activity factors and differences in activity by period of red-eared slider turtles (Trachemys scripta elegans) in Ansan Reed Wetland. Korean J Environ Ecol. 2019;33(6):645-53. https://doi. org/10.13047/KJEE.2019.33.6.645.

Jung JH. Activity factors and diet analysis of the red-eared slider turtle (Trachemy scripta) in Ansan Reed Wetland Park [MS thesis]. Seoul: Seoul National University; 2014.

Koo KS, Baek HJ, Kim SH, Jang HJ, Kim DI, Sung HC. First report on the natural movement of introduced turtle, Trachemys scripta elegans. Korean J Ecol Environ. 2019;52(1):9-12. https://doi.org/10. 11614/KSL.2019.52.1.009.

Koo KS, Chang MH, Song JY. A homerange study on the reeve's pond turtle (Chinemys reevesii) in the river environment. Korean Res Soc Herpetol. 2012;5:10.

Koo KS, Kwon S, Do MS, Kim S. Distribution characteristics of exotic turtles in Korean wild- based on Gangwon-do and Gyeongsangnamdo. Korean J Ecol Environ. 2017;50(3):286-94. https://doi.org/10. 11614/KSL.2017.50.3.286.

Koo KS, Song S, Choi JH, Sung HC. Current distribution and status of non-native freshwater turtles in the wild, Republic of Korea. Sustainability. 2020;12(10):4042. https://doi.org/10.3390/su12104042.

Lee H, Kim SH, Kim DE, Lee DH, Kim YC, Lee CW, et al. Nationwide survey of non-native species in Korea (I). Seocheon: National Institute of Ecology; 2015. p. 1-342. Korean.

Lowe S, Browne M, Boudjelas S, De Poorter M. 100 of the world's worst invasive species: a selection from the global invasive species database. Auckland: Invasive Species Specialist Group; 2000.

Macrotrends. South Korea urban population 1960-2021. 2021. https:// www.macrotrends.net/countries/KOR/south-korea/urban-population. Accessed 30 Aug 2021.

Mehta SV, Haight RG, Homans FR, Polasky S, Venette RC. Optimal detection and control strategies for invasive species management. Ecol Econ. 
2007;61(2-3):237-45. https://doi.org/10.1016/j.ecolecon.2006.10.024.

Ministry of Environment. Designation and notification of invasive alien species, Ministry of Environment notification 2016-112. 2016. https:// www.law.go.kr/LSW/admRulLsInfoP.do?admRulSeq=2100000049651. Accessed 20 Jul 2021. Korean.

Ministry of Environment. Ecosystem disturbing wildlife sourcebook. Gwacheon: Ministry of Environment; 2009. p. 1-138. Korean.

Ministry of Environment. Establishment and management of monitoring system for ecosystem disturbance species. Sejong: Ministry of Environment; 2006.212 p. Korean.

Morreale SJ, Whitfield Gibbons J, Congdon JD. Significance of activity and movement in the yellow-bellied slider turtle (Pseudemys scripta). Can J Zool. 1984;62(6):1038-42. https://doi.org/10.1139/z84148.

Oh HS, Park SM, Pradeep A, Kim YK, Kim TW, Han SH. Distribution and status of the alien invasive red-eared slider (Trachemys scripta elegans) in Jeju Island, South Korea. Korean J Environ Biol. 2017; 35(1):57-63. https://doi.org/10.11626/KJEB.2017.35.1.057.

Perez-Santigosa N, Díaz-Paniagua C, Hidalgo-Vila J. The reproductive ecology of exotic Trachemys scripta elegans in an invaded area of southern Europe. Aquatic Conserv: Mar Freshw Ecosyst. 2008;18: 1302-10. https://doi.org/10.1002/aqc.974.

Reed RN, Gibbons W. Conservation status of live U.S. nonmarine turtles in domestic and international trade: a report. Arlington: U.S. Fish and Wildlife Service; 2003.

Shea K, Chesson P. Community ecology theory as a framework for biological invasions. Trends Ecol Evol. 2002;17(4):170-6. https://doi. org/10.1016/S0169-5347(02)02495-3.

Taniguchi M, Lovich JE, Mine K, Ueno S, Kamezaki N. Unusual population attributes of invasive red-eared slider turtles (Trachemys scripta elegans) in Japan: do they have a performance advantage? Aquat Invasions. 2017;12(1):97-108. https://doi.org/10.3391/ai.2017.12.1.10.

Warwick C, Steedman C, Holford T. Ecological implications of the redeared turtle trade. Texas J Sci. 1990;42(4):419-22.

Yukalov VI, Yukalova EP, Sornette D. Extreme events in population dynamics with functional carrying capacity. Eur Phys J Spec Top. 2012;205:313-54. https://doi.org/10.1140/epjst/e2012-01577-3. 